Med Princ Pract 2017:26:299-300

DOI: $10.1159 / 000456664$

\section{Assessment of Platelet-to-Lymphocyte Ratio Can Be Affected by Several Factors}

\section{Mustafa Gulgun}

Department of Pediatric Cardiology, Gulhane Training and Research Hospital, Ankara, Turkey

\section{Dear Editor,}

I read the article by Gungor et al. [1] entitled "Association of Preoperative Platelet-to-Lymphocyte Ratio with Atrial Fibrillation after Coronary Artery Bypass Graft Surgery" [1] with interest. They investigated the relationship between platelet-to-lymphocyte ratio (PLR) and atrial fibrillation after coronary artery bypass graft surgery in adult patients, and reported that age and the PLR were independent predictors of atrial fibrillation after the surgery. I have a few comments.

A complete blood count is a widely used, automated, cost-effective, and readily accessible laboratory test for clinicians in daily routine, and it provides some valuable numeric data about formed blood content including red blood cells, white blood cells, and platelets. The total white blood cell count or platelets can be used as a marker of systemic inflammation, and the subtypes such as neutrophils or lymphocytes can also predict the presence of systemic inflammation even if the total white blood cell count is within the normal range [2]. The PLR can be calculated as the ratio of the platelet-to-lymphocyte count from a complete blood count. The PLR, as well as the neutrophil-to-lymphocyte ratio and the lymphocyte-to-platelet ratio, is used for assessment of the inflammation in many conditions [3]. Equally important, the PLR could be a prognostic factor for some diseases including malignancy, obstructive sleep apnea syndrome, and cardiovascular and renal diseases $[1,2]$. However, the PLR may be affected by several factors.

The lymphocyte cell count is influenced by age, gender, race, stress, physical activity, smoking, pregnancy, medications, infec- tions, splenectomy, and presence of antilymphocyte autoantibodies [4]. The time of sample collection, instruments, and equipment for processing and analyzing the blood may also contribute to variations in the lymphocyte counts. The lymphocyte cell count has a diurnal or circadian variation, resulting in a fluctuation in the number of T cells in the morning and night up to 20\% [3]. For the platelet count, methodology is essential for the PLR analysis; EDTA-induced pseudothrombocytopenia can be seen when EDTA-anticoagulated samples are used, and the higher platelet count can be obtained from the citrate-anticoagulated blood samples compared to those from the EDTA-anticoagulated blood samples [3]. However, in the study by Gungor et al. [1], there was no information about the time of sampling, processing, and equipment used for the patient's blood testing. In addition, it is clearly seen that there is a statistically significant difference between the patients with atrial fibrillation and the patients without atrial fibrillation regarding age.

Hence, I think that the implications of PLR analysis can be more powerful when a prospective study considering some methodological, physiological, and pathological confounding factors is performed. In this way, it can be revealed easily whether there is an association of preoperative PLR in the patients with atrial fibrillation after coronary artery bypass graft surgery.

\section{References}

1 Gungor H, Babu AS, Zencir C, et al: Association of preoperative plateletto-lymphocyte ratio with atrial fibrillation after coronary artery bypass graft surgery. Med Princ Pract 2016, DOI: 10.1159/000453614.

2 Yolbas S, Yildirim A, Gozel N, et al: Hematological indices may be useful in the diagnosis of systemic lupus erythematosus and in determining disease activity in Behçet's disease. Med Princ Pract 2016;25:510-516.

3 Isik A, Balcik OS, Akdeniz D, et al: Relationship between some clinical situations, autoantibodies, and pseudothrombocytopenia. Clin Appl Thromb Hemost 2012;18:645-649.

4 Shete A, Thakar M, Abraham PR, et al. A review on peripheral blood CD4+ T lymphocyte counts in healthy adult Indians. Indian J Med Res 2010;132:667-675.

\section{KARGER}

E-Mail karger@karger.com www.karger.com/mpp (c) 2017 S. Karger AG, Basel

\section{Karger} 0 pen access

This is an Open Access article licensed under the terms of the Creative Commons Attribution-NonCommercial 3.0 Unported license (CC BY-NC) (www.karger.com/OA-license), applicable to the online version of the article only. Distribution permitted for non-commercial purposes only.
Mustafa Gulgun, MD

Department of Pediatric Cardiology Gulhane Training and Research Hospital TR-06010 Etlik, Ankara (Turkey) E-Mail mustafagulgun@yahoo.com 


\title{
Reply
}

\author{
Hasan Gungor ${ }^{a}$, Abraham Samuel Babuc ${ }^{c}$, Cemil Zencir ${ }^{a}$, Mahmut Akpek $^{a}$, Mithat Selvi ${ }^{a}$, \\ Muhammet Huseyin Erkan ${ }^{b}$, Selim Durmaz ${ }^{b}$ \\ Departments of a Cardiology and ${ }^{\mathrm{b} C}$ Cardiovascular Surgery, Adnan Menderes University, Aydin, Turkey; \\ 'Department of Physiotherapy, School of Allied Health Sciences, Manipal University, Manipal, India
}

Dear Editor,

We would like to thank to Dr. Gulgun for his comments on our recent paper [1]. As outlined in his letter, the association between inflammatory markers such neutrophil-lymphocyte ratio, resistin, and atrial fibrillation after coronary artery bypass graft surgery have been described in several studies [2,3]. As Dr. Gulgun stated, these inflammatory markers are affected by several factors. In our previous study [3], serum samples to measure resistin level were collected in bottles before surgical intervention in the fasting state and immediately centrifuged at 2,000 rpm for $10 \mathrm{~min}$ and stored at $-70^{\circ} \mathrm{C}$ until assay. Patients with inflammatory bowel disease, malignancy, arthritis, and infections, as well as those taking steroids, were excluded.

In our recent retrospective study, the complete blood counts, which included total white blood cells, neutrophils, lymphocytes, and platelets, were collected in an EDTA-anticoagulated container with the patient in a fasting state, $24 \mathrm{~h}$ before surgery. Analysis of these samples was performed using an automated blood counter (BC-6800; Mindray, Shenzhen, China). Patients with infections and proinflammatory and autoimmune diseases, as well as who were on steroids or anti-inflammatory drugs, were excluded. How- ever, due to the nature of retrospective study, standardization is limited in all testing protocols, which might be overcome in a prospective study. Therefore, we do agree with Dr. Gulgun and believe the implications of PLR analysis can be more robust in a prospective study provided the highlighted methodological, physiological, and pathological confounding factors are considered.

\section{References}

1 Gungor H, Babu AS, Zencir C, et al: Association of preoperative plateletto-lymphocyte ratio with atrial fibrillation after coronary artery bypass graft surgery. Med Princ Pract 2016, DOI: 10.1159/000453614.

2 Gibson PH, Cuthbertson BH, Croal BL, et al: Usefulness of neutrophil/ lymphocyte ratio as predictor of new-onset atrial fibrillation after coronary artery bypass grafting. Am J Cardiol 2010;105:186-191.

3 Gungor H, Ayik MF, Kirilmaz B, et al: Serum resistin level: as a predictor of atrial fibrillation after coronary artery bypass graft surgery. Coron Artery Dis 2011;22:484-490.

Hasan Gungor, MD

Department of Cardiology

Faculty of Medicine, Adnan Menderes University

TR-09100 Aydin (Turkey)

E-Mail drgungorhasan@yahoo.com 